Pacific Journal of Mathematics

INEQUALITIES FOR FUNCTIONS REGULAR AND BOUNDED

CeCiL Craig, JR AND A. J.MACintyr 


\title{
INEQUALITIES FOR FUNCTIONS REGULAR AND BOUNDED IN A CIRCLE
}

\author{
Cecil Craig, Jr. and A. J. Macintyre
}

This paper is concerned with functions $w=f(z)$ regular and satisfying the inequality $|f(z)|<1$ in $|z|<1$. This class of functions will be denoted $E$.

We determine conditions on $z_{1}, z_{2}, z_{3}$ and $w_{1}, w_{2}, w_{3}$ for

$$
w_{k}=f\left(z_{k}\right)(k=1,2,3)
$$

to be possible with an $f(z)$ of $E$. In particular to map the vertices of the equilateral triangle $z_{k}=r e^{2 k \pi i / 3}$ into the vertices of another taken in the opposite direction $w_{k}=\rho e^{-2 k \pi i / 3}$ we must have $\rho \leqq r^{2}$. The extremal function associated with this problem is $w=z^{2}$. It seems convenient to discuss the fixed point if any of the mapping of $|z|<1$ into $|w|<1$. We include a simple proof of the theorem of Denjoy and Wolff that if no such fixed point exists then there is a unique distinguished fixed point on $|z|=1$. We give several results restricting the position of the interior or distinguished boundary fixed point in terms of the location of a zero of $f(z)$ or the value $f(0)$.

The theorem of Pick asserts that if $f(z)$ is in $E$ then $D\left(f\left(z_{1}\right), f\left(z_{\iota}\right)\right) \leqq D\left(z_{1}, z_{2}\right)$ where the nonEuclidean distance

$$
D\left(z_{1}, z_{2}\right)=\frac{1}{2} \log \frac{1+d\left(z_{1}, z_{2}\right)}{1-d\left(z_{1}, z_{2}\right)} \text { with } d\left(z_{1}, z_{2}\right)=\left|\frac{z_{1}-z_{2}}{1-\bar{z}_{2} z_{1}}\right| .
$$

Equality holds if and only if $f$ sets up a Möbius transformation. It follows from Pick's theorem that there can be at most one fixed point of $w=f(z)$ in $|z|<1$ unless $f(z) \equiv z$. It is usually sufficient when $f$ has an interior fixed point at $z=\alpha(\neq 0)$ to suppose $0<\alpha<1$.

Our first four theorems give information about the relative positions of zeros of $f$, an interior fixed point, and the value $f(0)$. We exclude the case where $f(z) \equiv z$.

Theorem 1. Let $f \in E$ and $f(0) \neq 0$. Then $f$ has no zeros in $|z|<|f(0)|$; and has a zero on $|z|=|f(0)|$ if and only if $f$ determines a Möbius transformation.

Proof. The image of $|z| \leqq|f(0)|$, which we denote by $C$ under the transformation $w=(z+f(0)) /(1+\overline{f(0)} z)$ is a circular disc $C^{\prime}$ having nonEuclidean center $f(0)$ with boundary passing through the origin. The function $w=f(z)$ takes the closed disc $C$ inside $C^{\prime}$ in the case $f$ 
is not a Möbius transformation so that $f(z) \neq 0$ for $z \in C$. If $f$ is linear, nonEuclidean distances are preserved and $f(0)$ is on the boundary of $C^{\prime}$.

THEOREM 2. Let $f \in E$ and let $z=\alpha$ be a fixed point of $f$ with $0<\alpha<1$. Then $f$ has no zeros inside $\left|z-\alpha /\left(1+\alpha^{2}\right)\right|=\alpha /\left(1+\alpha^{2}\right)$ and has a zero on the boundary if and only if $f$ determines a Möbius transformation.

Proof. The conclusion follows directly from Pick's theorem since the circle described is the nonEuclidean circle with nonEuclidean center $z=\alpha$.

If $f(0)$ is known in addition to the existence of an interior fixed point $\alpha(\neq 0)$, then these two results can be combined to give a larger region which is zero-free, namely the union of the two closed discs. The boundary zero of $f$ occurs at $z=\overline{f(0)}$ when $f$ is a Möbius transformation.

THEOREM 3. If $f \in E$ and $f(0) \neq 0$, then there can be no fixed point interior to the circle $C_{1}:|z|=\left(1-\sqrt{1-|f(0)|^{2}}\right) /|f(0)|$; and a fixed point on the boundary at $z_{0}=e^{i \arg f(0)}\left(1-\sqrt{\left.1-|f(0)|^{2}\right) /|f(0)|}\right.$ only if $f$ determines a Möbius transformation.

Proof. The nonEuclidean midpoint of the segment from 0 to $f(0)$ is $z_{0}$ (See Figure 1). A displacement of all points inside $C_{1}$ by $w=$ $f(z)$ insures there can be no fixed point interior to $C_{1}$. The boundary case is clear.

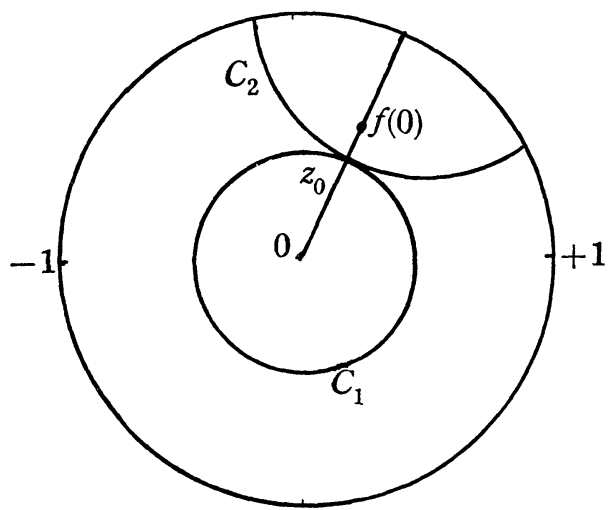

Figure 1.

If $f$ is known to have an interior fixed point, an improvement over Theorem 3 can be made as to its location based on a knowledge of $f(0)$. This is indicated in: 
THEOREM 4. Let $f \in E$. If $f$ has a fixed point $z=\alpha(\neq 0)$, in $|z|<1$, then $\alpha$ lies inside the circle $C_{2}$ passing through $z_{0}$ (Figure 1 ) with center at the geometric inverse of $f(0)$, relative to the unit circle and is on the boundary if and only if $f$ sets up an elliptic Möbius transformation.

Proof. This is a direct consequence of the inequality $D(\alpha, 0) \geqq$ $D(\alpha, f(0))$ where the point $z=\alpha$ is considered variable and $f(0)$ is fixed. The assumed interior fixed point is nearer $f(0)$ than the origin in the nonEuclidean sense, except when $f$ is linear. This requires an investigation of the nonEuclidean perpendicular bisector of the radial segment from 0 to $f(0)$. Straight lines of the Poincare model are Euclidean circles orthogonal to the unit circle. The Euclidean circle $C_{2}$ passing through the point $z_{0}$ and orthogonal to $|z|=1$ is the one described in the statement of the theorem.

Theorem 4 provides a simple proof of the Theorem of Denjoy on the fixed points of analytic transformations of the unit circle into itself [3]. It is convenient to develop the argument by formulating several variants of Theorem 4. $f(z)$ is supposed to belong to $E$.

THEOREM $4 \mathrm{~A}$. If $f(0) \neq 0$ and $\arg f(0)=\theta$, then any interior fixed point must lie in the half plane $R\left(e^{i \theta} z\right)>0$.

The half plane evidently contains the circle $C_{2}$ of Theorem 4 .

THEOREM 4B. The nonEuclidean bisector of the nonEuclidean segment joining $x$ and $f(x)$ divides the unit circle into two parts. Any interior fixed point must lie in the part containing $f(x)$ unless the function sets up an elliptic linear transformation when the fixed point must lie on the bisector.

This statement is equivalent to that of Theorem 4 . We have only to apply Theorem 4 to $w=T f\left(T^{-1} z\right)$ where $T$ is a linear transformation of $|z|<1$ into itself which carries $x$ to the origin.

THEOREM $4 \mathrm{C}$. If $x$ and $f(x)$ have the same argument, then any interior fixed point must lie on the same side as $f(x)$ of the circle through $x$ and orthogonal to the radius $O x$ and to $|z|=1$.

This follows from Theorem $4 \mathrm{~A}$. We consider $w=T f\left(T^{-1} z\right)$ where $T$ carries $x$ to the origin and the diameter through $x$ into itself.

Now consider $z=g(w)$ the solution of $w f(z)=z$. From Rouché's theorem $g(w)$ is regular and one valued for $w$ in $|w|<1$. Let $0<w<w^{\prime}<1$. Apply Theorem $4 \mathrm{C}$ to $F(z)=w^{\prime} f(z)$. Let $\alpha=g(w)$. We know that $F(\alpha)=w^{\prime} \alpha / w$. Any fixed point of $F(z)$ and that is to say $g\left(w^{\prime}\right)$ must lie in the smaller part of the unit circle partitioned 
as in Theorem $4 \mathrm{C}$. If $g(w)$ does not tend to a fixed point of $|w|<1$ as $w \rightarrow 1$ by positive values, it must converge to a point of $|z|=1$. This point on $|z|=1$ is the Denjoy distinguished fixed point. Calling such points $D$ fixed points it is clear that Theorem 4 applies to these as well as to interior fixed points.

We shall next be concerned with special cases of three point interpolation by $f \in E$. The problem first considered is that in which we require the vertices of an isosceles triangle to be mapped by $f$ into vertices of another isosceles triangle.

THEOREM 5. A necessary and sufficient condition for the existence of a function $f \in E$ taking points $z_{0}, 0, \bar{z}_{0}$ into $w, 0, \bar{w}$, respectively, is that $w=f\left(z_{0}\right)$ lies in lens $B=\left\{t \mid t=z_{0} \zeta, \zeta \in A\right\}$, where $A$ is the lens formed by the two circular arcs passing through $-1, z_{0},+1$ and $-1, \bar{z}_{0},+1$.

Proof. This follows from an inequality of G. Julia [4, 74-78] which for our problem is expressed by $D\left(w / z_{0}, \bar{w} / \bar{z}_{0}\right) \leqq D\left(z_{0}, \bar{z}_{0}\right)$. Since $D$ is a monotone increasing function of $d$, it is sufficient for our purpose to use $d$ and we shall refer to this as the nonEuclidean distance.

Let $\delta=\left|\left(z_{0}-\bar{z}_{0}\right) /\left(1-z_{0}^{2}\right)\right|$ and $\zeta=w / z_{0}=x+i y$. Then the basic inequality becomes $\left|(\zeta-\bar{\zeta}) /\left(1-\zeta^{2}\right)\right| \leqq \delta$ or $2|y| /\left|1-(x+i y)^{2}\right| \leqq \delta$. On squaring and simplifying we have $4 y^{2}\left(1-\delta^{2}\right) \leqq \delta^{2}\left(1-\left\{x^{2}+y^{2}\right\}\right)^{2}$. After taking square roots and rearranging we obtain

$$
x^{2}+\left(|y|+\frac{\sqrt{1-\delta^{2}}}{\delta}\right) \leqq\left(\frac{1}{\delta}\right)^{2} .
$$

If $y \geqq 0$, $\zeta$ lies on or below one circular arc; for $y<0$, $\zeta$ lies on or above the other arc, the reflection of the first in the real axis. These arcs form the boundary of a lens. To see that the boundary curves pass through $z_{0}$ and $\bar{z}_{0}$, consider the case of equality $|\zeta-\bar{\zeta}| /\left|1-\zeta^{2}\right|=$ $\left|z_{0}-\bar{z}_{0}\right| /\left|1-z_{0}^{2}\right|$. This equation describes the locus of a point which is a fixed nonEuclidean distance from its conjugate, in this case the nonEuclidean distance being $d\left(z_{0}, \bar{z}_{0}\right)$. The lens just described is labeled $A$ in Figure 2. To complete the proof one notes that $w=z_{0} \zeta$, for $\zeta \in A$, is the set of points of lens $B$.

A slightly more general result than Theorem 5 can be obtained. We require $f$ to be real at a real point $h$ as well as to take conjugate values at the conjugate pair $z_{0}, \bar{z}_{0}$.

THEOREM 6. A necessary and sufficient condition for the existence of a function $f \in E$ taking $z_{0}, h, \bar{z}_{0}$ into $w, h^{\prime}, \bar{w}$, respectively, where $h$ and $h^{\prime}$ are real numbers, is that $w=f\left(z_{0}\right)$ lies in a lens 


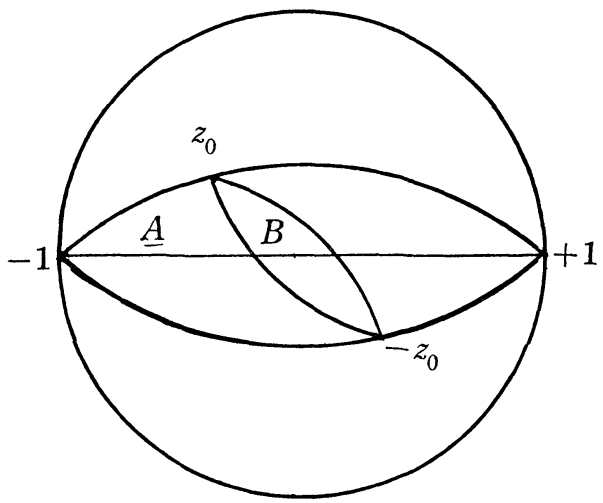

Figure 2.

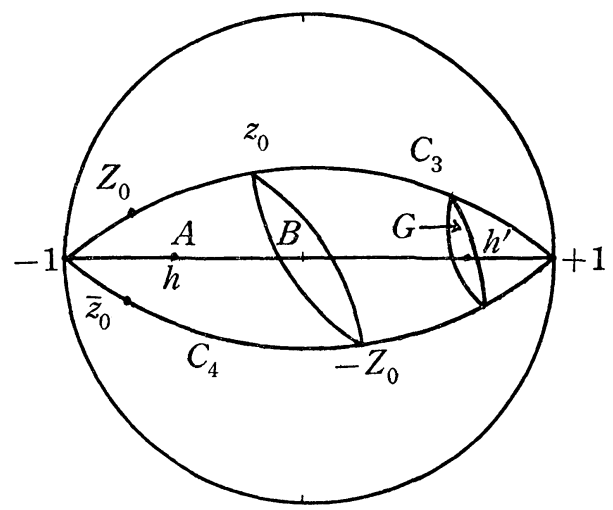

Figure 3.

$G=\left\{t \mid t=\left(W+h^{\prime}\right) /\left(1+h^{\prime} W\right), W \in B\right\}$, where

$$
B=\left\{W \mid W=Z_{0} \zeta, \zeta \in A, Z_{0}=\frac{z_{0}-h}{1-h z_{0}}\right\}
$$

and $A$ is the lens described in Theorem 5.

Proof. The proof depends on the fact that the composition of functions in $E$ is again in $E$. The transformation $Z=(z-h) /(1-h z)$ takes $h$ to zero with $z_{0}$ and $\bar{z}_{0}$ going to conjugate points $Z_{0}=$ $\left(z_{0}-h\right) /\left(1-h z_{0}\right)$ and $\bar{Z}_{0}$. Since this transformation preserves nonEuclidean distances, $z_{0}$ is moved to $Z_{0}$ on circular arc $C_{3}$ which passes through $-1, z_{0},+1$. By Theorem 5, a necessary and sufficient condition for the existence of a function of the class $E$ taking 0 to 0 and $Z_{0}, \bar{Z}_{0}$ into conjugate points, say $W$ and $\bar{W}$, is that $W$ lies in lens $B$ described in the statement of the theorem. Denote by $G$ the image of $B$ under the transformation $w=\left(W+h^{\prime}\right) /\left(1+h^{\prime} W\right)$. We conclude that $w=f\left(z_{0}\right)$ must lie in $G$, the lens enclosing $h^{\prime}$ with end points $\left(Z_{0}+h^{\prime}\right) /\left(1+h^{\prime} Z_{0}\right)$ and $\left(h^{\prime}-Z_{0}\right) /\left(1-h^{\prime} Z_{0}\right)$ on $C_{3}$ and $C_{4}$, respectively. 
If $f(z)$ is real for all $h,-1<h<+1$, we have the Carathéodory theorem [1,53] which asserts that if $f \in E$ and if, furthermore, $f$ is real for $z$ real, then a point $z$ inside lens $A$ has its image $f(z)$ also in this lens.

Finally, we investigate the Julia inequality in the case of a reversed equilateral triangle.

THEOREM 7. A necessary and sufficient condition for the existence of a function $f \in E$ which maps the vertices of the equilateral triangle, $r, r \omega, r \omega^{2}$ into the vertices of the reversed equilateral triangle $\rho, \rho w^{2}, \rho \omega$, respectively, is that $\rho \leqq r^{2}$.

Proof. The result is obtained by investigating the Julia condition: $D\left(A_{2}^{\prime} / a_{2}^{\prime}, A_{3}^{\prime} / a_{3}^{\prime}\right) \leqq D\left(a_{2}^{\prime}, a_{3}^{\prime}\right)$, where

$$
a_{2}^{\prime}=\frac{r(\omega-1)}{1-r^{2} \omega}, a_{3}^{\prime}=\frac{r\left(\omega^{2}-1\right)}{1-r^{2} \omega^{2}}, A_{2}^{\prime}=\frac{\rho\left(\omega^{2}-1\right)}{1-\rho^{2} \omega^{2}}, A_{3}^{\prime}=\frac{\rho(\omega-1)}{1-\rho^{2} \omega}
$$

and simplifying the somewhat involved expression. The computation is omitted.

In the extreme case $\rho=r^{2}$, the function $w=z^{2}$ performs the required interpolation.

\section{BIBLIOGRAPHY}

1. C. Carathéodory, Conformal Representation, Cambridge Math. Tracts, No. 28.

2. - Theory of Functions, Vol. II, Chelsea, 1960.

3. A. Denjoy, Sur l'itération des fonctions analytiques, C. R. Acad. des Sc. Paris 182 (1926), 255-257.

4. G. Julia, Principes géométriques d'analyse, Première partie, Paris 1930.

Received January 3, 1966.

UNIVERSITY OF CINCINNATI

UNIVERSITY OF CALIFORNIA, DAVIS 


\title{
PACIFIC JOURNAL OF MATHEMATICS
}

\author{
EDITORS
}

H. Samelson

Stanford University

Stanford, California

J. P. JANS

University of Washington

Seattle, Washington 98105

\section{J. DugundJI}

University of Southern California Los Angeles, California 90007

RICHARD ARENS

University of California

Los Angeles, California 90024

\section{ASSOCIATE EDITORS}

E. F. BECKENBACH

B. H. NeUmanN

F. WOLF

K. YosIDA

\section{SUPPORTING INSTITUTIONS}

UNIVERSITY OF BRITISH COLUMBIA

CALIFORNIA INSTITUTE OF TECHNOLOGY

UNIVERSITY OF CALIFORNIA

MONTANA STATE UNIVERSITY

UNIVERSITY OF NEVADA

NEW MEXICO STATE UNIVERSITY

OREGON STATE UNIVERSITY

UNIVERSITY OF OREGON

OSAKA UNIVERSITY

UNIVERSITY OF SOUTHERN CALIFORNIA

\author{
STANFORD UNIVERSITY \\ UNIVERSITY OF TOKYO \\ UNIVERSITY OF UTAH \\ WASHINGTON STATE UNIVERSITY \\ UNIVERSITY OF WASHINGTON \\ * \\ AMERICAN MATHEMATICAL SOCIETY \\ CHEVRON RESEARCH CORPORATION \\ TRW SYSTEMS \\ NAVAL ORDNANCE TEST STATION
}

Mathematical papers intended for publication in the Pacific Journal of Mathematics should be typewritten (double spaced). The first paragraph or two must be capable of being used separately as a synopsis of the entire paper. It should not contain references to the bibliography. Manuscripts may be sent to any one of the four editors. All other communications to the editors should be addressed to the managing editor, Richard Arens at the University of California, Los Angeles, California 90024.

50 reprints per author of each article are furnished free of charge; additional copies may be obtained at cost in multiples of 50 .

The Pacific Journal of Mathematics is published monthly. Effective with Volume 16 the price per volume (3 numbers) is $\$ 8.00$; single issues, $\$ 3.00$. Special price for current issues to individual faculty members of supporting institutions and to individual members of the American Mathematical Society: $\$ 4.00$ per volume; single issues $\$ 1.50$. Back numbers are available.

Subscriptions, orders for back numbers, and changes of address should be sent to Pacific Journal of Mathematics, 103 Highland Boulevard, Berkeley 8, California.

Printed at Kokusai Bunken Insatsusha (International Academic Printing Co., Ltd.), No. 6, 2-chome, Fujimi-cho, Chiyoda-ku, Tokyo, Japan.

PUBLISHED BY PACIFIC JOURNAL OF MATHEMATICS, A NON-PROFIT CORPORATION

The Supporting Institutions listed above contribute to the cost of publication of this Journal, but they are not owners or publishers and have no responsibility for its content or policies. 


\section{Pacific Journal of Mathematics}

\section{Vol. 20, No. $3 \quad$ November, 1967}

Dallas O. Banks, Lower bounds for the eigenvalues of a vibrating string whose density satisfies a Lipschitz condition ................... 393

Ralph Joseph Bean, Decompositions of $E^{3}$ which yield $E^{3} \ldots \ldots \ldots \ldots 411$

Robert Bruce Brown, On generalized Cayley-Dickson algebras ......... 415

Richard Dowell Byrd, Complete distributivity in lattice-ordered groups . . . 423

Roger Countryman, On the characterization of compact Hausdorff $X$ for

which $C(X)$ is algebraically closed ...................... 433

Cecil Craig, Jr. and A. J. Macintyre, Inequalities for functions regular and bounded in a circle ...................................... 449

Takesi Isiwata, Mappings and spaces ..................... 455

David Lewis Outcalt, Power-associative algebras in which every subalgebra is an ideal ..................................... 481

Sidney Charles Port, Equilibrium systems of stable processes .......... 487

Jack Segal, Quasi dimension type. I. Types in the real line ............ 501

Robert William Stringall, Endomorphism rings of primary abelian

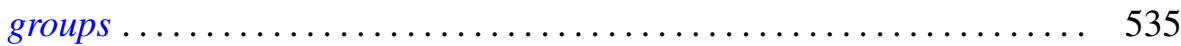

William John Sweeney, "The $\delta$-Poincaré estimate” ................. 559

L. Tzafriri, Operators commuting with Boolean algebras of projections of finite multiplicity ............................... 571 